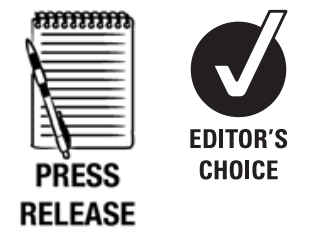

See Commentary, p 1012

${ }^{1}$ Royal Victoria Infirmary, Newcastle upon Tyne, UK ${ }^{2}$ University of Nottingham, Nottingham, UK ${ }^{3}$ CEEU Royal College of Physicians of London, London, UK ${ }^{4}$ John Radcliffe Hospital, Oxford, UK ${ }^{5} \mathrm{NHS}$ Blood and Transplant, Oxford, UK ${ }^{6}$ Western General Hospital, Edinburgh, UK

\section{Correspondence to}

Professor Richard F A Logan, Division of Epidemiology and Public Health, School of Community Health Sciences, University of Nottingham Medical School, Queen's Medical Centre, Nottingham NG7 2UH, UK; richard.logan@ nottingham.ac.uk

Revised 27 October 2009 Accepted 3 November 2009 Published Online First 31 March 2010

\title{
Use of endoscopy for management of acute upper gastrointestinal bleeding in the UK: results of a nationwide audit
}

\author{
Sarah A Hearnshaw, ${ }^{1}$ Richard F A Logan, ${ }^{2}$ Derek Lowe, ${ }^{3}$ Simon P L Travis, ${ }^{4}$ \\ Mike F Murphy, ${ }^{5}$ Kelvin R Palmer ${ }^{6}$
}

\section{ABSTRACT}

Objectives To examine the use of endoscopy in the UK for acute upper gastrointestinal bleeding (AUGIB) and compare with published standards.

To assess the organisation of endoscopy services for AUGIB in the UK.

To examine the relationship between outcomes and out of hours $(\mathrm{OOH})$ service provision.

Design Multi-centre cross sectional clinical audit. Setting All UK hospitals accepting admissions with AUGIB. Patients All adults ( $\geq 16$ yrs) presenting with AUGIB between 1st May and 30th June 2007.

Data Collection A custom designed web-based reporting tool was used to collect data on patient characteristics, comorbidity and haemodynamic status at presentation to calculate the Rockall score, use and timing of endoscopy, treatment including endoscopic, rebleeding and in-hospital mortality. A mailed questionnaire was used to collect data on facilities and service organisation.

Results Data on 6750 patients (median age 68 years) were analysed from 208 hospitals. 74\% underwent inpatient endoscopy; of these 50\% took place within $24 \mathrm{~h}$ of presentation, $82 \%$ during normal working hours and $3 \%$ between midnight and $8 \mathrm{am}$. Of patients deemed highrisk (pre-endoscopy Rockall score $\geq 5$ ) only $55 \%$ were endoscoped within $24 \mathrm{~h}$ and $14 \%$ waited $\geq 72 \mathrm{~h}$ for endoscopy. Lesions with a high risk of rebleeding were present in $28 \%$ of patients of whom $74 \%$ received endoscopic therapy. Further bleeding was evident in 13\% and mortality in those endoscoped was $7.4 \% 195 \% \mathrm{Cl}$ $6.7 \%$ to $8.1 \%$ ). In $52 \%$ of hospitals a consultant led out of hours $(\mathrm{OOH})$ endoscopy rota existed; in these hospitals $20 \%$ of first endoscopies were performed $00 \mathrm{H}$ compared with $13 \%$ in those with no $\mathrm{OOH}$ rota and endoscopic therapy was more likely to be administered (25\% vs $21 \%$ in hospitals with no $\mathrm{OOH}$ rota). The risk adjusted mortality ratio was higher (1.21, $\mathrm{p}=0.10,(95 \% \mathrm{Cl} 0.96$ to 1.51$))$ in hospitals without such rotas.

Conclusions This audit has found continuing delays in performing endoscopy after AUGIB and underutilisation of standard endoscopic therapy particularly for variceal bleeding. In hospitals with a formal $\mathrm{OOH}$ endoscopy rota patients received earlier endoscopy, were more likely to receive endoscopic therapy and may have a lower mortality.

Acute upper gastrointestinal bleeding (AUGIB) is a common medical emergency and is associated with a significant mortality. Its incidence has been

\section{Significance of this study}

What is already known about this subject?

- Therapeutic endoscopy after AUGIB has been clearly shown to reduce rebleeding and the need for surgery.

- Early endoscopy after AUGIB is believed to improve outcomes and is widely recommended in guidelines from the BSG and other organisations.

- In the UK access to out of hours endoscopy was only routinely available in $50 \%$ of hospitals admitting AUGIB patients in 2002.

\section{What are the new findings?}

- In this study only 50\% of AUGIB patients received endoscopy within $24 \mathrm{~h}$ of presentation.

- Of those with lesions regarded at high risk of rebleeding only $74 \%$ received endoscopic therapy including $64 \%$ of those with variceal bleeding.

- Only $52 \%$ of hospitals reported having a formal out of hours endoscopy rota but in these hospitals risk adjusted rebleeding and mortality rates were slightly lower than in those without a rota.

estimated to range from approximately 50-150 cases per 100000 population and it accounts for over 4000 deaths a year in the UK. ${ }^{1-7}$ Timely endoscopy plays a central role in the modern management of AUGIB with the value of endoscopic therapy for bleeding from peptic ulcers and oesophageal varices being well established. ${ }^{8-13}$

The British Society of Gastroenterology and the National Blood Service together sponsored a prospective audit of the management of patients presenting with AUGIB to UK hospitals during a 2month period in the summer of 2007. A previous audit carried out in 1993, also sponsored by the BSG and involving only four regions of England had found delays in undertaking endoscopy and underutilisation of endoscopic therapy leading the BSG guidelines to recommend inter alia that all medium to high risk patients with AUGIB be endoscoped within $24 \mathrm{~h}$, patients with major stigmata of recent haemorrhage should have endoscopic therapy and that hospitals managing AUGIB must have facilities for urgent endoscopy and agreed protocols for its management. ${ }^{10} 14$ This paper 
reviews the use of endoscopy in the management of AUGIB in the whole of the UK in 2007 and relates this to the pathways recommended in current guidelines. ${ }^{10}$

\section{METHODS}

All National Health Service (NHS) hospitals accepting acute admissions in the UK $(n=257)$ were invited to participate in the study. Two hundred and twenty-three agreed and 212 (84\%) hospitals submitted data. A list of the hospitals and clinicians contributing data is available at http://www.bsg.org.uk/clinical/ general/uk-upper-gi-bleeding-audit.html (accessed 16 December 2009).

In January 2007 participating hospitals were mailed a 4-page questionnaire enquiring about service arrangements for AUGIH in their hospitals. The questionnaire covered endoscopy facilities, site of blood transfusion laboratory, arrangements for OOH endoscopy, availability of nurse cover and existence of local guidelines for management of AUGIH.

\section{Case ascertainment and data collection}

A clinical lead in each hospital coordinated a team of caseidentifiers and data-collectors. Data were collected prospectively on all adults (16years or over) who presented with AUGIH between 1 May and 30 June 2007 (figure 1).

Cases were identified from hospital admission units, endoscopy departments, blood transfusion laboratories and all adult wards by the case-identifiers and preliminary data registered on a purpose designed website. In cases of uncertainty leads were asked to decide whether the cases were genuine AUGIB (using definitions in table 1 and from reviewing individual case notes), and only confirmed cases went on to have complete online data entry. Following discharge or death an online questionnaire was then completed by the designated data collectors. Information on demography, clinical (including medical co-morbidity and risk factors for AUGIH), laboratory, resuscitation, transfusion, endoscopy (including endoscopic therapy, re-bleeding), radiology, surgery, length of stay and mortality was extracted from the hospital records. All deaths within 30 days of presentation and occurring in hospital were included. Deaths occurring after leaving hospital were not included as they could not be readily identified. Compulsory fields on the questionnaire ensured a minimum dataset for completed eligible cases, which included the variables required to calculate the

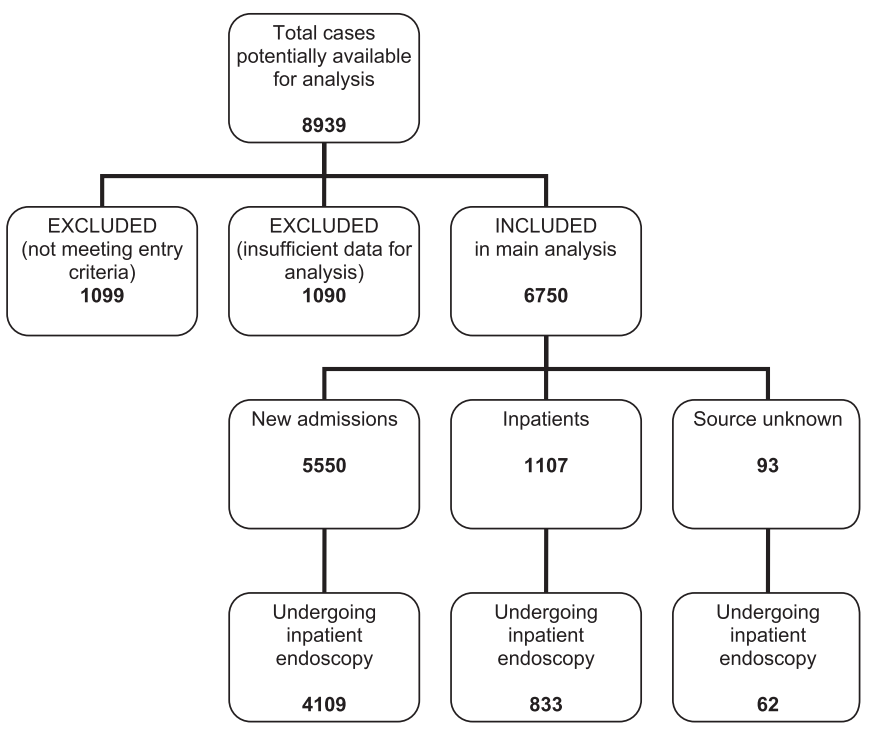

Figure 1 Flow chart showing numbers of excluded and included cases.
Rockall score. ${ }^{15}$ Haemodynamic status at presentation (ie, the first recorded pulse and blood pressure after presentation) was used along with age and medical co-morbidities to calculate preendoscopy (clinical) Rockall scores for all patients. Only patients with this complete data were included in the final analyses. Alcohol use and smoking history were also recorded where available. High risk patients were defined as having a pre-endoscopy Rockall score $\geq 5$ and medium risk patients defined as a score of 3 or 4 , based on previous mortality estimates of $11 \%$ (pre-score $=3$ ) and $40 \%$ (pre-score $=5$ ). ${ }^{15}$ The questionnaire included drop-down boxes with definitions and help text to increase the consistency of the data recording.

Each hospital was given a unique login and password. At no time did the study group have access to patient records or any patient-identifying data.

\section{Audit standards}

Standards for both the organisation of care and care process (the management of the patient from the time of presentation to death or discharge) were based on published guidelines and were approved by the Endoscopy committee of the British Society of Gastroenterology. ${ }^{8-11}$

\section{Data handling and analysis}

Data were exported electronically from the website into SPSS. Duplicate cases based on hospital, admission date and time, year of birth and admission full blood count values were removed from the data set prior to analysis. Hospital clinical leads were contacted for clarification of missing data as necessary. Pre(clinical) and post-endoscopy (complete) Rockall scores were calculated from data submitted for each patient. The complete score was used for internal risk adjustment to compare outcomes between patient groups. Comparisons were made between presenting characteristics and clinical outcomes of patients presenting to hospitals with formal out of hours $(\mathrm{OOH})$ on call endoscopy rotas and those presenting to hospitals without a formal rota.

Where data were missing from the organisational survey, the number of sites providing data is given. The web data entry ensured few missing data for clinical cases included in the analysis. For 20 of the 5004 cases who underwent UGI endoscopy, no time was given for the first endoscopy. For 15/5004 cases no record of endoscopic findings was provided. These cases

Table 1 Definitions

Acute upper gastrointestinal Haematemesis, the passage of melaena and/or firm bleeding (AUGIB) clinical or laboratory evidence of acute blood loss from the UGI tract within previous 10 days. Patients presenting with iron deficiency anaemia without evidence of acute UGI bleeding were not included.

Haematemesis Vomiting of blood or blood clots. Patients presenting with 'coffee ground' vomiting that was witnessed by medical or nursing staff were included.

Melaena $\quad$ The passage of dark tarry stools witnessed by medical or nursing staff or discovered on rectal examination.

High risk stigmata $\quad$ Red blood in the UGI tract, spurting or oozing, visible vessel, adherent clot for all diagnoses; red spot, wheal marking or nipple sign on varix/varices.

Re-bleeding Further haematemesis, passage of fresh melaena, continuing or recurring hypotension and tachycardia \pm fall in haemoglobin after the first endoscopy.

All cause mortality 
are included in the analyses and are reported in the "no endoscopic diagnosis' group.

\section{Statistical methods}

Patient data are presented as percentages with numerator/denominator and as summary statistics of median and inter-quartile ranges (IOR) or mean and standard deviation (SD) as appropriate.

To adjust for hospital clustering binary regression methods (using STATA 8 'binreg' software) were used to obtain risk ratios with $95 \%$ CIs when assessing the association between $\mathrm{OOH}$ endoscopy on-call rotas and process and outcome measures.

It was important to control for clustering at the hospital level in the statistical analysis. Because of similarities in practice styles and the organisation within hospitals, patients treated at the same hospital are more likely to receive similar care than are patients treated at different hospitals. Without adequate control for these similarities, CIs may be erroneous, depending on correlations between the outcomes for patients in each hospital cluster.

\section{RESULTS}

\section{Organisation of endoscopy services for AUGIB}

Organisational questionnaires were returned by 205 of 257 invited hospitals (80\%). Table 2 summarises the organisation of services in relation to standards derived from published guidelines. Local guidelines for AUGIB management existed in $80 \%$ $(165 / 205)$ of hospitals and $84 \%(172 / 205)$ of hospitals reported having audited their AUGIB outcomes in the past, 42\% (86/205) within the past 5 years.

While $92 \%$ of hospitals reported having facilities for the provision of endoscopy out of hours $(\mathrm{OOH})$ on site, only $52 \%$ reported having a formal $\mathrm{OOH}$ consultant rota for emergency endoscopy. $58 \%$ of hospitals had dedicated Monday-Friday

Table 2 Organisational aspects of AUGIB care

\begin{tabular}{|c|c|}
\hline Essential criteria* & Availability \% (n) \\
\hline $\begin{array}{l}\text { Facilities for undertaking endoscopy } \\
\text { for all patients presenting with AUGIB. }\end{array}$ & $\begin{array}{l}92 \%(189 / 205) \text { had } 00 \mathrm{H} \text { endoscopy } \\
\text { available on-site }\end{array}$ \\
\hline $\begin{array}{l}\text { Urgent endoscopy to be available out } \\
\text { of hours in high risk patients }(\mathrm{OOH} \text { on } \\
\text { call rota) }\end{array}$ & $\begin{array}{l}52 \%(106 / 205) \text { reported having an } \\
00 \mathrm{H} \text { endoscopy on call rota }\end{array}$ \\
\hline $\begin{array}{l}\text { Pulse oximetry monitoring to be used } \\
\text { in all sedated patients }\end{array}$ & $\begin{array}{l}91 \%(2963 / 3249) \text { of first } \\
\text { endoscopies excluding patients who } \\
\text { had general anaesthetic }\end{array}$ \\
\hline $\begin{array}{l}\text { ECG monitoring to be available for } \\
\text { high risk patients }\end{array}$ & $\begin{array}{l}47 \%(96 / 205) \text { of sites with this } \\
\text { available during } 00 \mathrm{H} \text { endoscopy }\end{array}$ \\
\hline $\begin{array}{l}\text { Blood pressure monitoring to be } \\
\text { available for high risk patients }\end{array}$ & $\begin{array}{l}80 \%(165 / 205) \text { of sites with this } \\
\text { available during } 00 \mathrm{H} \text { endoscopy }\end{array}$ \\
\hline $\begin{array}{l}\text { Endoscopists reported to be capable of } \\
\text { applying endoscopic haemostatic } \\
\text { therapies including: }\end{array}$ & $\mathrm{n}=647$ (consultants on rota) \\
\hline Ulcer injection, thermal or endoclip & $97 \%(626 / 647)$ \\
\hline Variceal banding & $76 \%(492 / 647)$ \\
\hline Variceal sclerotherapy & $80 \%(517 / 647)$ \\
\hline $\begin{array}{l}\text { Balloon tamponade for variceal } \\
\text { bleeding }\end{array}$ & $85 \%(552 / 647)$ \\
\hline \multicolumn{2}{|l|}{ Desirable criteria* } \\
\hline $\begin{array}{l}\text { Endoscopy to be available for patients } \\
\text { with AUGIB on daily list for those not } \\
\text { requiring } 00 \mathrm{H} \text { endoscopy }\end{array}$ & $\begin{array}{l}58 \%(119 / 205) \text { had a dedicated } \\
\text { Monday-Friday endoscopy slot }\end{array}$ \\
\hline $\begin{array}{l}\text { Nurses trained in the use of therapeutic } \\
\text { endoscopic techniques to be available } \\
\text { for all emergency endoscopy }\end{array}$ & $\begin{array}{l}37 \%(76 / 205) \text { had a nurses on-call } \\
\text { endoscopy rota }\end{array}$ \\
\hline $\begin{array}{l}\text { Trainees to be under direct supervision } \\
\text { for emergency endoscopy until passed } \\
\text { as competent }\end{array}$ & $\begin{array}{l}41 \%(666 / 1640) \text { of first endoscopies } \\
\text { performed by trainees were } \\
\text { performed under supervision }\end{array}$ \\
\hline
\end{tabular}

endoscopy slots for patients with AUGIB. Only 37\% of hospitals reported having an $\mathrm{OOH}$ rota for endoscopy nurse support.

\section{Recruitment and patient characteristics}

Two hundred and twelve hospitals submitted clinical data relating to 8939 patients. Subsequently some 1099 of these cases did not meet the audit entry criteria and were excluded by local hospital clinical leads. A further 1090 cases were potential cases for inclusion, but for local reasons only minimal and insufficient data were submitted. In 890 of these 1090 cases there were insufficient data to determine if the case was an AUGIB, whilst for 200 cases only minimal data were submitted. Consequently 6750 cases reported from 208 hospitals (median per hospital 31 IOR 16-43) were included in the analyses (figure 1). Four hospitals submitted $>80$ cases and 35 hospitals submitted $<10$ cases.

Table 3 summarises the baseline patient characteristics of all patients included and demonstrates slight variations between those undergoing inpatient endoscopy and those who did not. As expected fewer of the patients with very low pre-endoscopy Rockall scores underwent inpatient endoscopy compared with those with higher scores. In contrast levels of comorbidity due to stroke, dementia, and cancer were higher in those not endoscoped.

Table 3 Patient characteristics at time of admission or as recorded at time of inpatient presentation

\begin{tabular}{|c|c|c|c|}
\hline Variable & $\begin{array}{l}\text { Endoscopy \% } \\
(n=5004)\end{array}$ & $\begin{array}{l}\text { No } \\
\text { Endoscopy \% } \\
(\mathrm{n}=1746)\end{array}$ & $\begin{array}{l}\text { All } \\
\text { patients } \% \\
(n=6750)\end{array}$ \\
\hline \multicolumn{4}{|l|}{ Gender* } \\
\hline Male & $61(3040)$ & $55(969)$ & 59 (4009) \\
\hline Female & 39 (1962) & $45(777)$ & $41(2739)$ \\
\hline \multicolumn{4}{|l|}{ Admission status } \\
\hline New & 82 (4109) & $83(1441)$ & $82(5550)$ \\
\hline Inpatient & $17(833)$ & $16(274)$ & 17 (1107) \\
\hline Unknown & $1.2(62)$ & $1.8(31)$ & $1.4(93)$ \\
\hline \multicolumn{4}{|l|}{ Age years } \\
\hline Median (IOR) & $68(51-80)$ & $67(43-83)$ & $68(49-81)$ \\
\hline \multicolumn{4}{|c|}{ Age group distribution } \\
\hline$<60$ & $35(1771)$ & $43(746)$ & $37(2517)$ \\
\hline $60-79$ & $38(1922)$ & $24(412)$ & $35(2334)$ \\
\hline$\geq 80$ & $26(1311)$ & $34(587)$ & 28 (1898) \\
\hline \multicolumn{4}{|c|}{ Haemodynamic status at presentation } \\
\hline Normal & $60(3026)$ & $66(1155)$ & $62(4181)$ \\
\hline $\begin{array}{l}\text { Tachycardia only } \\
\text { (>100 bpm) }\end{array}$ & $24(1177)$ & $18(320)$ & 22 (1497) \\
\hline $70 \leq \mathrm{BP}<100$ & $13(628)$ & $10(175)$ & $12(803)$ \\
\hline $50 \leq \mathrm{BP}<70$ & $1.5(73)$ & $1.7(30)$ & $1.5(103)$ \\
\hline $\mathrm{BP}<50$ & $0.3(17)$ & $0.3(6)$ & $0.3(23)$ \\
\hline Not recorded & $1.7(83)$ & $3.4(60)$ & $2.1(143)$ \\
\hline \multicolumn{4}{|l|}{ Co-morbidity $(\%) \dagger$} \\
\hline IHD & $19(973)$ & $15(260)$ & $18(1233)$ \\
\hline Cardiac failure & $5.7(283)$ & $6.1(107)$ & $5.8(390)$ \\
\hline Respiratory disease & $11(540)$ & $12(202)$ & $11(742)$ \\
\hline Cirrhosis & $10(522)$ & $4.4(77)$ & $8.9(599)$ \\
\hline Renal disease & $8.2(412)$ & $7.6(132)$ & $8.1(544)$ \\
\hline Stroke & $6.9(347)$ & $9.5(166)$ & $7.6(513)$ \\
\hline Dementia & $4.3(214)$ & 11 (187) & $5.9(401)$ \\
\hline Cancer & $8.0(399)$ & $9.3(162)$ & $8.3(561)$ \\
\hline \multicolumn{4}{|c|}{ Pre endoscopy Rockall score } \\
\hline $0-1$ & 32 (1589) & $41(716)$ & $34(2305)$ \\
\hline $2-3$ & 33 (1635) & 23 (399) & $30(2034)$ \\
\hline $4-5$ & $30(1515)$ & 29 (499) & 30 (2014) \\
\hline $6-7$ & $5.3(265)$ & $7.6(132)$ & $5.9(397)$ \\
\hline
\end{tabular}

*Gender not known in two cases, both of whom had endoscopy.

†Precise definitions for all conditions were provided to data collectors.

$\mathrm{BP}$, systolic blood pressure $(\mathrm{mm} \mathrm{Hg}) ; \mathrm{IHD}$, ischaemic heart disease. 
Table 4 Timing of first endoscopy, rebleeding and mortality

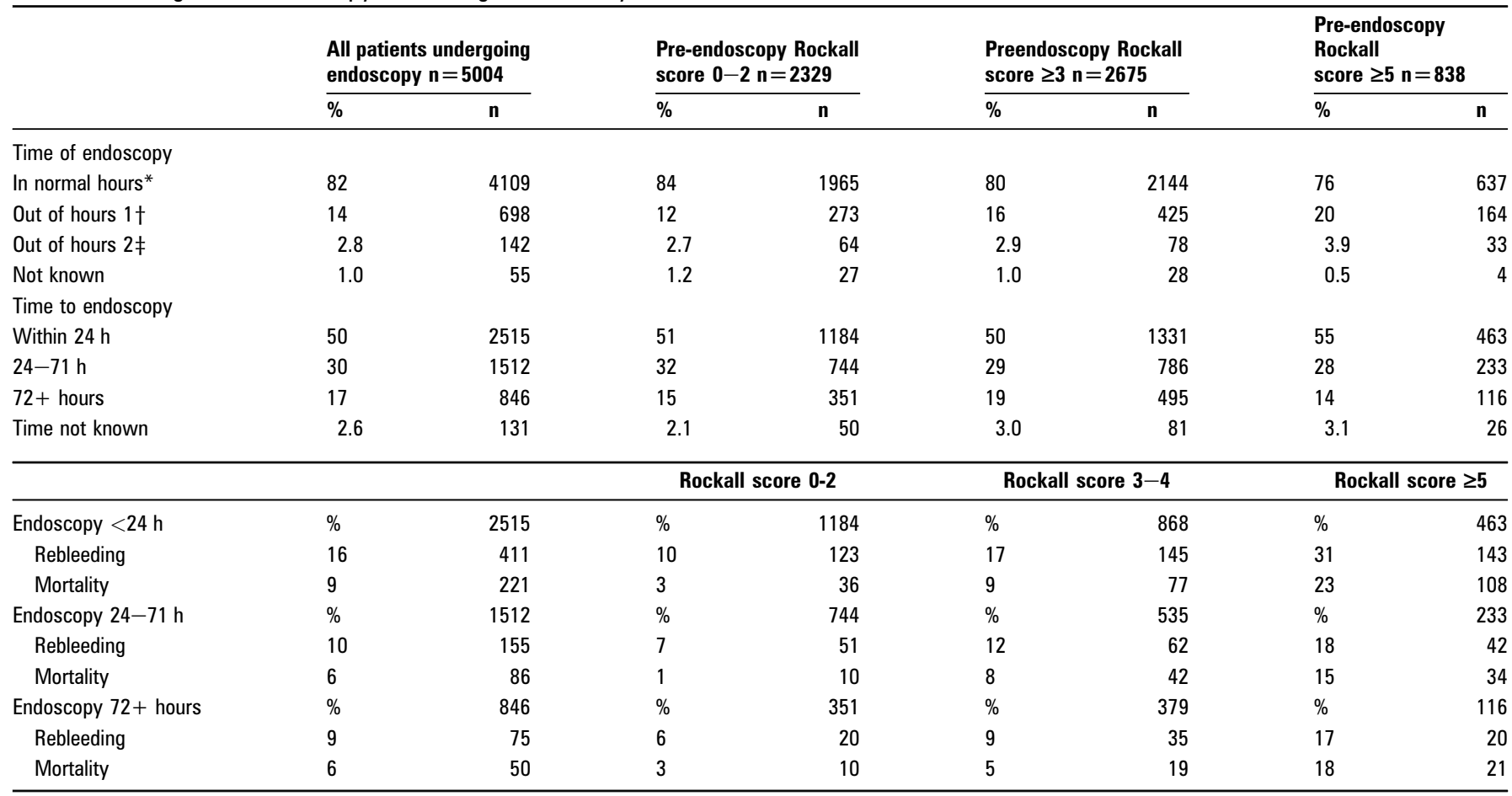

*8 am-5 pm, Monday-Friday.

$\dagger 5 \mathrm{pm}$ to midnight Monday-Friday and $8 \mathrm{am}$ to midnight Saturday/Sunday.

‡Midnight to 8 am all days.

\section{Timing of first endoscopy and its relationship to rebleeding and mortality}

The median time from presentation to endoscopy was $23 \mathrm{~h}$ (IOR $12-51)$. Most patients (59\%) presented out of hours with $20 \%$ presenting between midnight and 8 am but as shown in table 4 the majority (82\%) of endoscopies were performed during normal working hours. Medium and high risk patients (preendoscopy Rockall score $\geq 3$ ) had a similar distribution of times to endoscopy as low risk patients. As many as $42 \%$ of high risk patients (pre-endoscopy Rockall score $\geq 5$ ) waited more than $24 \mathrm{~h}$ for their first endoscopy and 14\% waited more than $72 \mathrm{~h}$. Nevertheless a greater proportion of high risk patients (24\%) had their first endoscopy performed outside normal working hours than the low risk patients (15\%).

As shown in table 4 rebleeding after endoscopy occurred in a greater percentage $(16 \%)$ of cases endoscoped within $24 \mathrm{~h}$ of admission compared with later $(10 \%)$ and this was evident at all levels of pre-endoscopy Rockall score. Mortality was also higher in those cases endoscoped with $24 \mathrm{~h}(9 \%)$ compared with later $(6 \%)$ and this again was evident at all levels of pre-endoscopy Rockall score. However it should be emphasised that such comparisons have not been and cannot be adjusted for the selection of sicker cases for early endoscopy or for the selective loss of cases dying before endoscopy was performed.

\section{Sedation for endoscopy}

No intravenous sedation was administered to $32 \%(1595 / 5004)$ of patients while $3.3 \%(167 / 5004)$ of patients received a general anaesthetic for their first endoscopy. Of the remainder, $65 \%$ $(3242 / 5004)$ received intravenous sedation (midazolam, fentanyl, pethidine, or diazemuls either alone or in combination). The median (IOR) dose of midazolam administered was $3 \mathrm{mg}(2-4 \mathrm{mg})$. There were 28 patients $(0.6 \%)$ who required flumazenil at the first endoscopy and 125 patients $(2.5 \%)$ were reported to have had significant desaturation.

\section{Endoscopic diagnoses}

Data on endoscopic diagnoses are shown in table 5 showing that more than one endoscopic diagnosis was commonly made. At least one abnormality was detected in 81\% (4043/5004) of patients.

Table 5 Main endoscopic diagnoses (from all endoscopies)

\begin{tabular}{lcr}
\hline Diagnosis & $\begin{array}{c}\text { \% of 5004 } \\
\text { endoscoped }\end{array}$ & n \\
\hline Any peptic ulcer disease (PUD) & 36 & 1826 \\
PUD alone & 20 & 1024 \\
Any varices & 11 & 544 \\
Varices alone & 4.0 & 199 \\
Any portal hypertensive gastropathy & 5.5 & 275 \\
(PHG) & & \\
PHG alone & 0.5 & 25 \\
PHG and varices only & 2.7 & 134 \\
Any malignancy & 3.7 & 187 \\
$\quad$ Malignancy alone & 2.7 & 133 \\
$\quad$ Malignancy and PUD & 0.7 & 33 \\
$\quad$ Malignancy and erosive disease & 0.4 & 18 \\
(any of oesophagitis, gastritis, & & \\
$\quad$ duodenitis) & 24 & 1177 \\
Any oesophagitis & 8.9 & 443 \\
$\quad$ Oesophagitis alone & 22 & 1091 \\
Any gastritis/erosions & 7.2 & 360 \\
$\quad$ Gastritis/erosions alone & 13 & 640 \\
Any erosive duodenitis & 2.3 & 114 \\
$\quad$ Erosive duodenitis alone & 4.3 & 213 \\
Any Mallory-Weiss tear & 2.1 & 106 \\
$\quad$ Mallory-Weiss alone & 2.7 & 133 \\
Other (any)* & 19 & 961 \\
No abnormality seen & 50 & 2484 \\
One diagnosis only & 23 & 1146 \\
Two diagnoses & 8.3 & \\
Three or more diagnoses & & \\
\hline$*$ I & &
\end{tabular}

*Includes angiodysplasia, vascular ectasia, arteriovenous malformation, haemobilia. 
Table 6 Outcomes after endoscopy

\begin{tabular}{|c|c|c|c|c|c|}
\hline \multirow[b]{2}{*}{ Patient group after first endoscopy } & \multirow{2}{*}{$\begin{array}{l}\text { Number } \\
\text { in group }\end{array}$} & \multicolumn{2}{|c|}{ Re-bleeding } & \multicolumn{2}{|c|}{$\begin{array}{l}\text { In hospital } \\
\text { mortality }\end{array}$} \\
\hline & & $\%$ & n & $\%$ & n \\
\hline $\begin{array}{l}\text { Any peptic ulcer } \\
\text { disease }\end{array}$ & 1745 & 17 & 288 & 8.7 & 151 \\
\hline Any varices & 526 & 26 & 135 & 15 & 80 \\
\hline \multicolumn{6}{|l|}{ Complete Rockall score } \\
\hline $0-2$ & 1408 & 4.9 & 69 & 0.9 & 13 \\
\hline $3-5$ & 2204 & 10 & 229 & 5.7 & 125 \\
\hline $6-8$ & 1225 & 25 & 304 & 15 & 179 \\
\hline$>8$ & 152 & 43 & 65 & 35 & 53 \\
\hline $\mathrm{SRH}^{*}$ & 1550 & 29 & 442 & 13 & 208 \\
\hline Endoscopic therapy & 1172 & 26 & 308 & 12 & 140 \\
\hline All & 5004 & 13 & 668 & 7.4 & 371 \\
\hline
\end{tabular}

${ }^{*}$ Any stigmata of recent haemorrhage including blood in the upper Gl tract with no specific lesion seen.

\section{Outcomes after first endoscopy}

As shown in table 6 there were 1550 patients at the first endoscopy who had stigmata of recent haemorrhage (SRH) present. Mortality in patients with endoscopic SRH was 13\% (208) and 29\% (442) had evidence of rebleeding (including bleeding that continued after endoscopy) following the first endoscopy. Of all patients undergoing endoscopy 13\% (668/5004) had clinical evidence of rebleeding. $19 \%$ of these (125) went on to require surgery or interventional radiology, and $27 \%$ (183) of patients with rebleeding died.

Of patients receiving endoscopic therapy $(n=1172)$ - whether or not they had endoscopic SRH- 26\% (308) had evidence of re-bleeding or continued bleeding and mortality was $12 \%$ (140).

Of the 535 patients with endoscopic SRH who did not receive endoscopic therapy, 29\% (154) had evidence of bleeding and mortality was $15 \%(79)$.

\section{Endoscopic therapy}

Data were provided on use of endoscopic therapy in 99\% (4942/ 5004) of patients for the first endoscopy. Of these, 24\% (1172/ 4942) received endoscopic therapy. Use of therapy increased to $42 \%(250 / 594)$ for second and $51 \%$ (46/91) for third endoscopies. Blood was found at endoscopy in 20\% (985/5004) and 61\% (597/ 985) of these patients received some type of endoscopic therapy. Table 7 gives details of the use of therapy at the first endoscopy for each of the specific endoscopic stigmata associated with high risk of haemorrhage, and shows significant variation in therapy rates according to which stigmata were identified. The use of therapy in patients with varices was low at $64 \%(339 / 526)$ but rose to over $90 \%$ when the varices showed clear signs of recent bleeding.
The commonest endoscopic therapy was ulcer base injection, which comprised $58 \%$ (684/1172) of therapeutic procedures at the first endoscopy. For patients with non-variceal AUGIB who received therapy, bimodal haemostasis was used in 38\% (315/ 833). For patients with varices at the first endoscopy who received therapy $(64 \%, 339 / 526)$ the majority underwent variceal banding (84\%, 283/339). Fourteen patients required balloon tamponade for varices after the first endoscopy. At a second endoscopy $20 \%(103 / 523)$ of patients with varices had banding or injection therapy.

\section{Proton pump inhibitor therapy}

Intravenous proton pump inhibitor (PPI) therapy was given to $48 \%$ (3225/6750) of all patients (including 547 of 1746 who did not have an endoscopy) and $89 \%(2885 / 3225)$ of these were given prior to any endoscopy. Intravenous PPI was started or continued in $24 \%$ (1215/5004) of patients after the first endoscopy and 70\% (848/ 1215) of these patients had SRH. Some 10\% (338/3319) of patients without SRH received intravenous PPI after the first endoscopy.

\section{Repeat endoscopy}

Twelve per cent $(594 / 5004)$ of patients had a repeat inpatient endoscopy. For 35\% (206/594) of these, continued or re-bleeding was stated as the sole reason for doing a repeat endoscopy, whilst for $33 \%$ (197) the sole reason was to check or repeat previous endoscopic therapy. Both reasons were stated for a further $7 \%$ (46). Of patients receiving therapy at the first endoscopy, 306/1170 (26\%) had a second inpatient endoscopy. $1742 / 5004$ (35\%) had high risk lesions (any SRH and/or any varices) identified at the first endoscopy and thus warranted repeat inpatient endoscopy.

$20 \%(997 / 5004)$ of patients had a repeat endoscopy planned as an outpatient.

\section{Other outcomes after endoscopy}

One hundred and eight patients (2.2\%) underwent surgery for AUGIB after endoscopy, for re-bleeding or high risk lesions. These 108 patients had a median post-endoscopy Rockall score of 6 and the majority $(77 \%, 88 / 108)$ had a peptic ulcer diagnosed at endoscopy. Surgical mortality was 31\% (34/108). Eighty-four patients underwent interventional radiology of whom 22 had embolisation and six had TIPS procedures performed; of the 8414 died.

\section{Relationship between service provision and outcomes}

Table 8 compares the characteristics of patients admitted to 104 hospitals with a formal $\mathrm{OOH}$ endoscopy rota with those of patients admitted to 81 hospitals without such a rota. Patients in

Table 7 Stigmata of recent haemorrhage and use of endoscopic therapy* at first endoscopy

\begin{tabular}{|c|c|c|c|c|c|}
\hline & $\begin{array}{l}\% \text { of } \\
5004 \dagger(n)\end{array}$ & $\begin{array}{l}\text { Therapy given } \\
\text { (n) }\end{array}$ & $\begin{array}{l}\text { Rebleeding } \neq \\
\text { (n) }\end{array}$ & $\begin{array}{l}\text { No therapy } \\
\text { given }(n)\end{array}$ & $\begin{array}{l}\text { Rebleeding } \neq \\
\text { (n) }\end{array}$ \\
\hline Visible vessel & $6.3 \%$ (318) & $92 \%(292)$ & $28 \%(82)$ & $8 \%(26)$ & $38 \%(10)$ \\
\hline Spurting vessel & $2.9 \%(145)$ & $93 \%(135)$ & $41 \%(55)$ & $7 \%(10)$ & $60 \%(6)$ \\
\hline $\begin{array}{l}\text { Dark spot in } \\
\text { ulcer base }\end{array}$ & $1.7 \%(83)$ & $64 \%(53)$ & $15 \%(8)$ & $36 \%(30)$ & $35 \%(39)$ \\
\hline All varices & $11 \%(526)$ & $64 \%(339)$ & $29 \%(99)$ & $36 \%(184)$ & $20 \%(36)$ \\
\hline $\begin{array}{l}\text { Varices with } \\
\text { nipple sign }\end{array}$ & $0.4 \%(18)$ & $94 \%(17)$ & $41 \%(7)$ & $6 \%(1)$ & 0 \\
\hline
\end{tabular}

*BSG guidelines (2002) advise endoscopic therapy for actively bleeding ulcers, non bleeding visible vessels and ulcers with adherent clot when technically possible and use of banding in preference to sclerotherapy for varices if possible.

tIn 62 cases data on whether endoscopic therapy was used was missing.

$\neq$ Defined as rebleeding or continued bleeding. 
hospitals with such a rota had slightly higher rates of inpatient endoscopy. They also had higher rates for the first endoscopy occurring out of normal working hours and for it taking place within $24 \mathrm{~h}$, particularly for medium and high risk patients. Patients admitted to hospitals with formal $\mathrm{OOH}$ endoscopy were more likely to receive endoscopic therapy at the first endoscopy. The risk-adjusted post-endoscopy in-hospital mortality was $21 \%$ higher for patients in hospitals without formal OOH endoscopy rotas $(1.21,95 \% \mathrm{CI} 0.96$ to 1.51$)$ but this was of borderline statistical significance $(p=0.10)$.

\section{DISCUSSION}

In this large audit of endoscopy in AUGIB which has involved over $75 \%$ of UK hospitals we have found continuing deficiencies in the provision and use of endoscopy for AUGIB. While $92 \%$ of hospitals reported having facilities for undertaking $\mathrm{OOH}$ endoscopy only a half had an endoscopy on call rota that would ensure an endoscopist would be available if needed. Of those endoscoped only $50 \%$ had an endoscopy within 24 h of presentation with AUGIB. This figure has not increased since the 1993 audit even though it is prominently recommended in the BSG guidelines and those of other organisations. ${ }^{8-11}$ Furthermore the proportion was only a little higher at $55 \%$ for patients deemed to be at high risk with clinical Rockall scores of 5 or more. Use of endoscopic therapy for high risk lesions has also increased little since 1993 with 77\% (766/989) of patients with visible or spurting vessels or varices being treated compared with $72 \%$ $(136 / 190)$ with these findings in $1993 .^{14}$

About a half of the hospitals (52\%) involved reported having an $\mathrm{OOH}$ endoscopy rota or service with a consultant available on call. After adjusting for case mix differences there was evidence that in these hospitals endoscopy for AUGIB was being

Table 8 Hospitals with $00 \mathrm{H}$ endoscopy on call vs. those without $\mathrm{OOH}$ on call: patient characteristics and outcomes

\begin{tabular}{|c|c|c|c|c|c|}
\hline & \multirow{2}{*}{\multicolumn{2}{|c|}{$\begin{array}{l}104 \text { Hospitals with } 00 \mathrm{H} \text { on } \\
\text { call endoscopy* } \\
\text { All patients }=3499\end{array}$}} & \multirow{2}{*}{\multicolumn{2}{|c|}{$\begin{array}{l}81 \text { Hospitals with no } 00 \mathrm{H} \text { on } \\
\text { call } \\
\text { endoscopy* } \\
\text { All patients }=2821\end{array}$}} & \multirow{3}{*}{$\begin{array}{l}\text { Rockall-adjusted ratio for Hospitals with } \\
\text { no } 00 \mathrm{H} \text { on call endoscopy relative to } \\
\text { those that have } 00 \mathrm{H} \text { on call endoscopy } \\
(95 \% \mathrm{Cl}) \text {, p value }\end{array}$} \\
\hline & & & & & \\
\hline & $\%$ & $\mathbf{n}$ & $\%$ & $\mathbf{n}$ & \\
\hline New admissions & 83 & 2896 & 81 & 2297 & \\
\hline Inpatients & 16 & 572 & 17 & 469 & \\
\hline Not known & 0.9 & 31 & 1.9 & 55 & \\
\hline Median age yrs (IOR) & \multicolumn{2}{|l|}{$67(48-81)$} & \multicolumn{2}{|l|}{$70(50-81)$} & \\
\hline \multicolumn{6}{|l|}{ Pre-endoscopy score: } \\
\hline $0-1$ & 35 & 1208 & 33 & 938 & \\
\hline $2-3$ & 30 & 1040 & 31 & 868 & \\
\hline $4-5$ & 30 & 1056 & 30 & 839 & \\
\hline $6-7$ & 5.6 & 195 & 6.2 & 176 & \\
\hline In-hospital mortality & 9.2 & 322 & 10.4 & 293 & $1.09(0.93$ to 1.29$), p=0.29 \dagger$ \\
\hline Median length of stay days (IOR) & $6(2-16)$ & 3476 & $5(2-15)$ & $\mathrm{n}=2789$ & $0.93(0.84$ to 1.02$), p=0.13 \dagger$ \\
\hline Length of stay $>7$ days & 43 & 1478 & 40 & 1105 & \\
\hline \multirow[t]{3}{*}{ Having an inpatient endoscopy } & 78 & 2721 & 71 & 2001 & $0.91(0.86$ to 0.97$) \mathrm{p}=0.004 \dagger$ \\
\hline & \multicolumn{2}{|c|}{ Endoscopy $=n=2721$} & \multicolumn{2}{|c|}{ Endoscopy $=n=2001$} & \\
\hline & $\%$ & $\mathbf{n}$ & $\%$ & $\mathbf{n}$ & \\
\hline \multicolumn{6}{|l|}{ Timing of first endoscopy: } \\
\hline In hours & 79 & 2154 & 86 & 1726 & \\
\hline $\mathrm{OOH} 1$ & 16 & 431 & 11 & 221 & \\
\hline $\mathrm{OOH} 2$ & 3.8 & 104 & 1.6 & 33 & \\
\hline Not known & 1.2 & 32 & 1.0 & 21 & \\
\hline $\mathrm{OOH}(\mathrm{OOH} 1$ or $0 \mathrm{OH} 2)$ & 20 & 535 & 13 & 234 & $0.64(0.49$ to 0.84$), p=0.001 \dagger$ \\
\hline \multicolumn{6}{|l|}{ Time to first endoscopy (hours): } \\
\hline All patients: median (IOR), n & $22(10-47)$ & 2629 & $25(14-60)$ & 1923 & $0.89(0.81$ to 0.98$), p=0.02 \dagger$ \\
\hline All patients: within $24 \mathrm{~h}$ & 55 & 1439 & 48 & 931 & $0.84(0.75$ to 0.94$), p=0.002 \dagger$ \\
\hline Pre-endosc Rockall $\geq 3$ : median (IQR), $n$ & $22(9-48)$ & 1417 & $25(13-69)$ & 1015 & \\
\hline Pre-endosc Rockall $\geq 3$ : within $24 \mathrm{~h}$ & 55 & 782 & 47 & 472 & \\
\hline \multicolumn{6}{|l|}{ Post endoscopy Rockall score } \\
\hline $0-2$ & 29 & 776 & 27 & 549 & \\
\hline $3-5$ & 42 & 1144 & 46 & 919 & \\
\hline $6-7$ & 19 & 528 & 19 & 376 & \\
\hline $8+$ & 9.7 & 263 & 7.6 & 153 & \\
\hline Not known & 0.4 & 10 & 0.2 & 4 & \\
\hline Endoscopic therapy at first endoscopy & 25 & 685 & 21 & 419 & $0.88(0.79$ to 0.99$), p=0.03 \neq$ \\
\hline In-hospital mortality (post-endoscopy) & 6.9 & 188 & 8.0 & 60 & $1.21(0.96$ to 1.51$), p=0.10 \neq$ \\
\hline $\begin{array}{l}\text { Rebleeding including continued } \\
\text { bleeding (post-endoscopy) }\end{array}$ & 14 & 368 & 13 & 255 & $0.97(0.82$ to 1.15$), p=0.72 \ddagger$ \\
\hline Surgery (post-endoscopy) & 2.2 & 61 & 2.1 & 42 & $0.97(0.64$ to 1.47$), p=0.89 \ddagger$ \\
\hline
\end{tabular}

In hours-Mon-Fri 8 am-5 pm; 00H1-Mon-Fri 5 pm-midnight, Saturday-Sunday 8 am-midnight; 00H2-Midnight-8 am all days.

*Data regarding whether or not there was an $\mathrm{OOH}$ on call rota were missing for 430 patients.

†Risk adjustment using pre-endoscopy Rockall score $(0-1,2-3,4-5,6-7)$ and hospital clustering effects using binary regression (see statistical methods).

$\neq$ Risk adjustment using complete post-endoscopy Rockall score $(0-2,3-5,6-7,8+)$ and hospital clustering effects using binary regression (see statistical methods) 
undertaken earlier and more often $\mathrm{OOH}$ than in hospitals without this service. However the differences were not large and this reflects the fact that even in hospitals without a formal on call rota $13 \%$ of endoscopies were being performed $\mathrm{OOH}$ compared with $20 \%$ in the others. Not only does this make it difficult to detect differences in outcomes between the two groups it implies a substantial amount of good-will activity by consultants and trainees in these hospitals without an $\mathrm{OOH}$ service. There was evidence that endoscopic therapy was used significantly more often in the hospitals with an $\mathrm{OOH}$ service but this did not seem to have had an effect on the occurrence of continued or rebleeding. Nevertheless risk adjusted mortality was about $20 \%$ higher in hospitals without an $\mathrm{OOH}$ service. After adjusting for hospital clustering in a multilevel analysis this difference fell just short of statistical significance (OR 1.21, $95 \%$ CI 0.96 to 1.51 ) and may therefore be a chance observation. If it does indicate a real effect then it is unlikely to be a direct result of $\mathrm{OOH}$ endoscopy and use of endoscopic therapy as there was no reduction in the occurrence of continued or rebleeding. It more likely reflects greater interest and a higher priority given to AUGIB in hospitals with an $\mathrm{OOH}$ service.

This study is based on systematically collected data from a large number of prospectively identified cases and provides a comprehensive picture of current endoscopy practice for AUGIB in the UK. There were however 45 hospitals invited to take part that did not, including at least two known to have units dedicated to the management of AUGIB. Nevertheless recent figures for case mix, rebleeding and mortality reported from one of these units were remarkably similar to these reported here. ${ }^{16}$ By using a two stage case ascertainment process we hoped to ensure ascertainment of consecutive cases and avoid any selection bias. To examine whether our data might have been biased by some of the 208 hospitals contributing a small number of selected cases we reanalysed the data after removing hospitals reporting the fewest $5 \%, 10 \%$ and $25 \%$ of cases in turn and found that mortality rates changed little when hospitals reporting few cases were removed from the analysis. While recording of data was clearly dependent on accurate extraction of data from endoscopy and other clinical records the use of online data collection tools provided a largely clean and complete dataset.

There have been two earlier surveys of the provision of $\mathrm{OOH}$ endoscopy services in the UK and it is disappointing that the proportion of hospitals providing a formal $\mathrm{OOH}$ service (ie, an on call rota of endoscopists) has not increased from the $50 \%$ reported by 150 hospitals in 2002 and the $49 \%$ reported in $2005 .{ }^{17} 18$

There have been few other studies in the UK which collected data on the timing and use of endoscopy since the previous audit performed in $1993 .{ }^{14}$ Reports from three hospitals with dedicated units for AUGIB indicate that endoscopy within $24 \mathrm{~h}$ is achievable in the UK albeit only in the last report was a figure (82\%) quoted. ${ }^{1619} 20$ In many other countries endoscopy within $24 \mathrm{~h}$ of presentation with AUGIB is regarded as standard although there is a lack of published data to confirm how widely this is really occurring. Vreeburg et al reported that in $199478 \%$ of cases in the Amsterdam area were endoscoped within $24 \mathrm{~h}$ and this figure had risen to $80 \%$ by $2000 .{ }^{3}{ }^{4}$ Data from the RUGBE cohort in Canada showed that in 1999-2002 76\% of their patients were endoscoped within $24 \mathrm{~h}$ and $90 \%$ within $48 \mathrm{~h}$ which compares well with the $83 \%$ within $72 \mathrm{~h}$ in this audit. ${ }^{21} \mathrm{~A}$ recent US study using a nationwide database of hospital admissions found that in 2004 endoscopy was being performed within one day of admission in over $80 \%$ of admissions with variceal bleeding. ${ }^{22}$ A similar analysis restricted to peptic ulcer bleeding found that $78 \%$ of these admissions had been endoscoped by day $2 .^{23}$ In France albeit in 1996 the practice was closer to that in the UK with only $70 \%$ being endoscoped within $48 \mathrm{~h} .{ }^{24}$

The value of early endoscopy in AUGIB has been debated for many years. ${ }^{25-27}$ Its proponents have argued that early endoscopy allows early identification of variceal bleeding, provides the opportunity for endoscopic haemostasis, risk stratification of non variceal bleeding and so allows early discharge of low risk patients. It has been difficult to show consistent reductions in rebleeding, need for surgery or length of hospital stay whether early has been defined as within a few hours of presentation or within $24 \mathrm{~h}$. No study has been able to demonstrate that early endoscopy leads to a reduction in mortality. Nevertheless the BSG guidelines along with others emphasise the importance of endoscopy within $24 \mathrm{~h}$ of presentation particularly for high risk patients and this view was reiterated by the BSG endoscopy committee immediately prior to the start of the audit. ${ }^{8-11}$

Comparisons with the findings from the 1993 audit are inevitable but need to be made cautiously given the differences in the geographic coverage and the differences in data collection particularly with regard to more precise definition and coding of comorbidity. Comparing our data with the first audit unadjusted mortality following endoscopy appears to have fallen by $25 \%$ $(10 \%-7.4 \%) .{ }^{14}$ Unadjusted rates for re-bleeding also appear to have fallen $(19 \%-13 \%)$ and surgery rates have reduced by over $70 \%$ from $7.8 \%$ in 1993 to $2.2 \%$ in $2007 .{ }^{14}$ (Hearnshaw et al, paper in preparation). Moreover a recent analysis of mortality following 400000 admissions for non variceal AUGIB identified in the Hospital Episode Statistics for England provides support for some, if not all, of the decline in mortality being real with a small but statistically significant decline in mortality being evident between 1999 and $2005 .^{28}$ Factors unrelated to endoscopy are likely to have contributed to these improvements. These include the increasing use of proton pump inhibitors for peptic ulcer bleeding and vasopressor therapy for variceal bleeding as well as general improvements in health reflected in increases in UK life expectancy. Comparing the patient characteristics with those in the 1993 study, a similar proportion had peptic ulcers diagnosed at endoscopy ( $36 \%$ vs $35 \%$ ), but twice as many had varices diagnosed (11\% vs $4.3 \%) .{ }^{14}$ In view of the convincing evidence for the benefits from endoscopic therapy, and the rise in the frequency of variceal bleeding, the shortfall in endoscopic competence identified here, particularly for variceal therapies, is an important and previously unreported deficiency in UK endoscopy service provision. As there is increasing evidence now for the benefit of applying more than one endoscopic technique to bleeding peptic ulcers ${ }^{13}$ it will be important to establish the competence and availability of endoscopists with regard to other therapeutic techniques such as use of heater probe and endoclips for bleeding peptic ulcers.

\section{CONCLUSIONS}

This audit has revealed serious deficiencies in the use of endoscopy for AUGIB in the UK. While $60 \%$ of patients with AUGIB present $\mathrm{OOH}$ and almost a fifth of endoscopies are being performed $\mathrm{OOH}$ in a half of UK hospitals contributing to this audit there is no $\mathrm{OOH}$ service and in these hospitals $\mathrm{OOH}$ endoscopies are reliant on the goodwill of consultants and trainees. Despite these deficiencies there appears to have been a reduction in numbers needing surgery and in case mortality since the 1993 audit.

Acknowledgements The authors are immensely grateful to all the consultants, trainees and others responsible for data collection in the participating hospitals and to NHS Blood and Transplant and the British Society of Gastroenterology for supporting the clinical research fellow in undertaking this study. We would also like to thank 
Professor Tim Rockall for his input into the initial design of this study and recommendations for analyses.

Funding Dr S Hearnshaw was funded to conduct this study by NHS Blood and Transplant and the British Society of Gastroenterology. No participating hospitals were provided with funding.

\section{Competing interests None.}

Contributors Dr S Hearnshaw designed the study, ran the data collection, analysed the data and wrote the manuscript.

Mr D Lowe contributed to the design of the study, carried out the statistical analysis and co-wrote the manuscript.

Prof R Logan designed the study, advised on data analysis and contributed to the writing of the manuscript.

Dr S Travis contributed to the study design and writing of the manuscript.

Prof M Murphy designed the study and contributed to the writing of the manuscript. Dr K Palmer designed the study, contributed to the writing of the manuscript and is the guarantor.

Provenance and peer review Not commissioned; externally peer reviewed.

\section{REFERENCES}

1. Rockall TR, Logan RF, Devlin HB, et al. Incidence and mortality from acute upper gastrointestinal haemorrhage in the United Kingdom. Br Med $J$ 1995:311:222-6.

2. Taha AS, Angerson WJ, Knill-Jones RP, et al. Upper gastrointestinal haemorrhage associated with low-dose aspirin and anti-thrombotic drugs - a 6-year analysis and comparison with non-steroidal anti-inflammatory drugs Aliment. Pharmacol Ther 2005:22:285-9.

3. van Leerdam ME, Vreeburg EM, Rauws EA et al. Acute upper GI bleeding: did anything change? Time trend analysis of incidence and outcome of acute upper $\mathrm{Gl}$ bleeding between 1993/4 and 2000. Am J Gastroenterol 2003;98:1494-9.

4. Vreeburg EM, Snel P, de Bruijne JW, et al. Acute upper gastrointestinal bleeding in the Amsterdam area: incidence, diagnosis and clinical outcome. Am J Gastroenterol 1997:92:236-43

5. Czernichow P, Hochain P, Nousbaum JB, et al. Epidemiology and course of acute upper gastrointestinal haemorrhage in four french geographical areas. Eur $J$ Gastroenterol Hepatol 2000;12:175-181.

6. Paspatis GA, Matrella E, Kapsoritakis A, et al. An epidemiological staudy of acute upper gastrointestinal bleeding in Crete, Greece. Eur J Gastroenterol Hepatol 2000;12:1215-20.

7. Blatchford 0, Davidson L, Murray W, et al. Acute upper gastrointestinal haemorrhage in west of Scotland: case ascertainment study. Br Med J 1997;315:510-14.

8. Barkun A, Bardou M, Marshall JK. Nonvariceal upper GI Bleeding Consensus Conference Group. Consensus recommendations for managing patients with nonvariceal upper gastrointestinal bleeding. Ann Intern Med 2003;139:843-57.

9. American Society for Gastrointestinal Endoscopy guideline. The role of endoscopy in acute non-variceal upper GI hemorrhage. Gastrointest Endosc 2004:4:497-501.
10. British Society of Gastroenterology Endoscopy Committee. Non-variceal upper gastrointestinal haemorrhage: guidelines. Gut 2002;51(Suppl IV):iv1-6.

11. Jalan R, Hayes PC. UK guidelines on the management of variceal haemorrhage in cirrhotic patients. Gut 2000:46: $1111-15$.

12. Cook DJ, Guyatt G, Salena B, et al. Endoscopic therapy for acute non-variceal haemorrhage: a meta-analysis. Gastroenterol 1992:102:139-48.

13. Vergara M, Calvet X, Gisbert JP. Epinephrine injection versus epinephrine injection and a secondary endoscopic method in high risk bleeding ulcers. Cochrane Database Syst Rev 2007;2:CD005584. doi:10.1002/14651858.CD005584.pub2.

14. Rockall TA, Logan RF, Devlin HB, et al. Influencing the practice and outcome in acute upper gastrointestinal haemorrhage. Gut 1997; 41:606-11.

15. Rockall TR, Logan RF, Devlin HB, et al. Risk assessment after acute upper gastrointestinal haemorrhage. Gut 1996;38:316-21.

16. Sidhu R, Sakellariou P, McAlindon ME, et al. Dedicated bleed units: should they be advocated? Eur J Gastroenterol Hepatol 2009;21:861-65.

17. Douglass A, Bramble M, Barrison I. National Survey of emergency endoscopy units. Br Med J 2005;330:1000-1.

18. Gyawali P, Suri D, Barrison I, et al. A discussion of the British Society of Gastroenterology survey of emergency gastroenterology workload. Clin Med 2007; 7:585-88.

19. Masson J, Bramley PN, Herd K, et al. Upper gastrointestinal bleeding in an open-access dedicated unit. J $R$ Coll Physicians Lond 1996;30:436-42.

20. Lim CH, Vani D, Shah SG, et al. The outcome of suspected upper gastrointestinal bleeding with 24-hour access to upper gastrointestinal endoscopy: a prospective cohort study. Endoscopy 2006;38:581-85.

21. Barkun A, Sabbah S, Enns R, et al. The Canadian Registry on Nonvariceal Upper Gastrointestinal Bleeding and Endoscopy (RUGBE): Endoscopic hemostasis and proton pump inhibition are associated with improved outcomes in a real-life setting. Am J Gastroenterol 2004;99:1238-46.

22. Ananthakrishnan AN, McGinley EL, Saeian K. Outcomes of weekend admissions for upper gastrointestinal hemorrhage: a nationwide analysis. Clin Gastroenterol Hepatol 2009:7:296-302

23. Shaheen AAM, Kaplan GG, Myers RP. Weekend versus weekday admission and mortality from gastrointestinal hemorrhage caused by peptic ulcer disease. Clin Gastroenterol Hepatol 2009; 7:303-10.

24. Amouretti M, Czernichow P, Kerjean A, et al. [Management of upper digestive hemorrhage occurring in the community: patterns of patient care in 4 French administrative areas]. Gastroenterol Clin Biol 2000;24:1003-11. French.

25. Spiegel BMR, Vakil NB, Ofman JJ. Endoscopy for acute nonvariceal upper gastrointestinal tract hemorrhage: is sooner better? Arch Intern Med 2001:161:1393-404.

26. Tsoi KK, Ma TK, Sung JJ. Endoscopy for upper gastrointestinal bleeding: how urgen is it? Nat Rev Gastroenterol Hepatol 2009;6:463-9.

27. Cooper GS, Kou TD, Wong RCK. Use and impact of early endoscopy in elderly patients with peptic ulcer hemorrhage: a population-based analysis. Gastrointest Endosc 2009;70:229-35.

28. Crooks C, Card TR, West J. Trends in mortality of non-variceal upper gastrointestinal haemorrhage in England: analysis of hospital admissions 1999 to 2005. Gut 2009:58(Suppl 11):A43. 